ORIGINAL ARTICLE

\title{
Barriers to physical activity in patients with diabetes
}

\author{
N Thomas, E Alder, G P Leese
}

Postgrad Med J 2004;80:287-291. doi: 10.1136/pgmj.2003.010553

See end of article for authors' affiliations .....................

Correspondence to: Dr Graham P Leese, Ward 1 and 2, Ninewells Hospital, Dundee DD1 9SY, Scotland, UK; graham.leese@tuht.scot. nhs.uk

Submitted 30 May 2003 Accepted 7 August 2003

\begin{abstract}
Purpose: Two questions were addressed: (1) How much physical activity do patients with diabetes perform? (2) What are the perceived factors that prevent patients from doing more physical activity? Research design and methods: Interview based questionnaires were distributed to consecutive patients attending the Diabetes Clinic, Ninewells Hospital, Dundee over a period of five months. Exclusion criteria were age below 20 years and inadequate understanding of English; 428 questionnaires were given out with 406 completed.

Results: Physical activity was undertaken by $34 \%$ of patients with diabetes and only $9 \%$ of these patients exercised sufficiently to achieve a large change in heart rate or breathing. The main reasons for inactivity included perceived difficulty taking part in exercise, feelings of tiredness, and being distracted by something good on television. Lack of time and lack of local facilities also contributed.

Conclusions: Few patients with diabetes participate in physical activity, and in those who do the level of intensity is low. There are many modifiable factors distracting patients from exercise.
\end{abstract}

$\mathrm{P}$ hysical activity as shown by meta-analysis improves glycaemic control as measured by glycated haemoglobin (HbAlc). ${ }^{1}$ Such improvement in HbAlc is likely to reduce microvascular complications and it is likely that physical activity will improve risk of cardiovascular disease, which is the commonest cause of death in patients with diabetes. ${ }^{2}$ Physical inactivity is a risk factor for coronary heart disease $^{3}$ and is associated with a 3-4-fold increased risk of mortality from all causes over an eight year follow up. ${ }^{4}$ In addition to reducing deaths from coronary heart disease, ${ }^{5}$ physical activity also improves glycaemic control through various mechanisms, ${ }^{6}$ thus delaying the onset and reducing the incidence of diabetes and its related clinical endpoints such as nephropathy, retinopathy, neuropathy, cardiovascular and peripheral vascular disease. Several large studies have shown lifestyle intervention involving regular moderate physical activity to significantly reduce the incidence of type 2 diabetes. ${ }^{7-9}$ Regular physical activity has also been shown to improve psychological wellbeing and self esteem. ${ }^{10}$

Physical activity is an important factor in reducing morbidity from diabetes and maintaining quality of life. However recent studies have shown that adults with diabetes may undertake less physical activity than non-diabetic individuals, ${ }^{11}{ }^{12}$ up to one third of adults with diabetes are completely sedentary, and only a third exercise regularly. ${ }^{13}$

Although physical activity is encouraged, long term compliance is a major problem with physical activity programmes. Many patients fail to maintain self motivated home based physical activity when not in an exercise class. Personal and environmental barriers have been associated with failure to participate or maintain physical activity. ${ }^{14-16}$

In view of this, we surveyed physical activity levels within patients with diabetes patients attending the hospital clinic and examined reasons preventing them from performing more physical activity.

\section{METHODS}

Ethical approval was obtained from the Tayside Committee on Medical Research Ethics. An interview based questionnaire was given to consecutive patients attending the Diabetes Centre, Ninewells Hospital, Dundee. Exclusion criteria were under 20 years of age or inadequate English.

A research nurse explained the purpose of the study and obtained consent. The duration of diabetes, current mode of treatment, level of glycaemic control (HbAlc), and weight were recorded from the notes.

The first part of the questionnaire asked about levels of physical activity in the past two weeks. The data collection was based on the US Vital Statistics Survey (1990), modified to include UK orientated past-times. ${ }^{17}$ The second half of the questionnaire explored the underlying psychology based on the Health Belief model that has been widely used in health psychology. ${ }^{18}$ Questionnaires were given to 428 participants, two refused, 20 had poor eyesight, and 406 (95\%) were completed. The Flesch reading ease score was 59.4, and where patients had difficulty understanding or were unable to read the form, the research nurse read it for them and explained it to them.

\section{Sample population}

The sample consisted of 224 men and 182 women. The mean age was 56.5 years, ranging from 20 to 84 . The mean duration of diabetes was 10.0 years. Altogether $44 \%$ were treated with insulin, $39 \%$ with tablets, and $18 \%$ on diet control alone. Patients whose diabetes had begun before the age of 30 and who were started on insulin within a year of diagnosis were classified as type 1 diabetes. Patients whose diabetes had been diagnosed after the age of 30 and who were not started on insulin within a year of diagnosis were classified as type 2 . The population comprised $19 \%$ with type 1 and $81 \%$ type 2 diabetes, which is representative of the region as a whole. ${ }^{19}$

\section{Statistics}

Data is presented as mean (SD). The levels of activity were compared using the $\chi^{2}$ test for proportions and $t$ test for individual differences, or Wilcoxon if the data were not normally distributed. A level of $\mathrm{p}<0.05$ was deemed statistically significant for these comparisons of activity levels. The $\chi^{2}$ test was used for comparisons of psychological variables, but since a large number of variables were compared, a significance level of $\mathrm{p}<0.01$ was used. A bivariate regression analysis was performed to determine the most important psychological variables.

\section{RESULTS \\ Activity}

In the whole group a third $(n=135,33 \%)$ said that they had taken part in exercise, sport, or physically active hobbies in 
Table 1 Sample population; values are mean (SD)

\begin{tabular}{clll}
\hline & Active & Inactive & $p$ Value \\
\hline All patients & $\mathrm{n}=135$ & $\mathrm{n}=271$ & \\
Age (years) & $52.9(149)$ & $57.4(13.9)$ & 0.008 \\
Weight $(\mathrm{kg})$ & $78.8(14.6)$ & $79.9(15.6)$ & 0.5 \\
Type 2 diabetes & $\mathrm{n}=105$ & $\mathrm{n}=224$ & \\
Age (years) & $59.0(13.4)$ & $61.9(10.4)$ & 0.05 \\
Weight $(\mathrm{kg})$ & $79.4(15.1)$ & $81.4(15.7)$ & 0.27 \\
Type 1 diabetes & $\mathrm{n}=30$ & $\mathrm{n}=47$ & \\
Age (years) & $31.9(9.8)$ & $35.9(6.9)$ & 0.05 \\
Weight $(\mathrm{kg})$ & $76.5(12.8)$ & $72.9(13.9)$ & 0.24 \\
\hline
\end{tabular}

the last two weeks. These patients were categorised as "active" and the remainder $(\mathrm{n}=271,67 \%)$ were categorised as "inactive". There were no differences between males and females.

Those who were active were more likely to be younger, but there was no difference in weight between those who were active and those who were not (table 1). Glycaemic control was no different between active and inactive patients (8.1(1.8)\% $v$ 8.3(5.6)\% respectively; not normally distributed; Wilcoxon test non-significant). In patients with type 1 diabetes, activity was not associated with age or weight, and the same was true for type 2 diabetes (table 1). Patients with type 1 diabetes were significantly younger than those with type 2 patients in both the inactive (35.9 (6.9) $v 61.9$ (10.4) years, $\mathrm{p}<0.001)$ and active group (31.9 (9.8) $v 59.0$ (13.4) years, $\mathrm{p}<0.001$ ). In the inactive group, patients with type 1 diabetes were significantly lighter than patients with type-2 diabetes $(72.9$ (13.9) $v 81.4$ (15.7) $\mathrm{kg}, \mathrm{p}<0.01)$. In active patients however there was no significant weight difference between patients with type 1 and type 2 diabetes (76.5 (12.8) v 79.4 (15.1) kg, p=0.3).

For "active" patients with type 2 diabetes $(\mathrm{n}=105), 22 \%$ were controlled with diet treatment, $40 \%$ with tablets and $38 \%$ with insulin. The corresponding figures for inactive patients with type 2 diabetes were, $21 \%, 52 \%$, and $27 \%$ respectively (not significant; $\mathrm{p}=0.09$ ).

The most popular activities were walking $(96 \%)$, gardening $(52 \%)$, general exercise $(21 \%)$, and swimming (13\%). These four activities were analysed in greater detail (table 2). A guide to the intensity of exercise is indicated by whether a small or large increase in heart rate or breathing was achieved. For all activities only $9.1 \%$ of patients recorded a "large" change in heart rate or breathing and 51.3\% recorded no change in heart rate or breathing (table 2).

\section{Factors influencing activity}

Patients were asked to select from a list which events, if any, resulted in them performing significantly less exercise than they had previously been doing. The following prompts were cited as reasons for doing less physical activity: serious illness $(20 \%, n=115)$, changing jobs $(9 \%, n=35)$, having children
(4\%, $\mathrm{n}=16)$, developing diabetes $(3 \%, \mathrm{n}=14)$, moving house $(3 \%, \mathrm{n}=10)$, starting first job $(2 \%, \mathrm{n}=9)$, getting married $(2 \%, \mathrm{n}=7)$, getting separated $(2 \%, \mathrm{n}=6)$, and leaving home $(\mathrm{n}=1)$.

Active patients were less likely to think exercise was difficult, that lack of local facilities were an obstacle, and that they had no spare time. Active patients were more likely to continue exercise if tired or depressed, if there was something good on television, if the weather was poor, if they had no exercise partner, or if they had more hypoglycaemic episodes than usual than inactive patients (tables 3 and 4).

Active patients were also more positive, believing that strenuous exercise would aid diabetic control and were less likely to think that exercise would increase the chance of hypoglycaemia.

Initial deterrents for inactive patients under 60 included lack of local facilities (26\%), cost of exercise facilities (23\%), and lack of spare time $(25 \%)$. These patients were also less likely to exercise if the weather was bad $(56 \%)$, if they were tired $(54 \%)$, or if they had other plans with friends $(50 \%)$ (table 3).

Patients under 60 years were more likely to believe that strenuous exercise would improve their diabetic control compared with patients over 60, whether active $(79 \% v$ $27 \%$ ) or inactive ( $88 \% v 44 \%)$. Active patients under 60 years of age were less likely to believe that strenuous exercise would cause hypoglycaemia compared with the over $60 \mathrm{~s}$ $(66 \% v 40 \%)$. This was echoed when comparing inactive patients under 60 with those over 60 (82\% v 72\%).

In a bivariate regression analysis, the most significant factors influencing physical activity irrespective of age and type of diabetes included a perceived difficulty in taking part in exercise $(p<0.0001)$, tiredness $(p<0.0001)$, if there was something good on television $(p=0.0003)$, lack of local facilities $(p=0.03)$, and lack of spare time $(p=0.012)$. This suggests that social factors may be more significant in discouraging physical activity than health related concerns (table 5).

\section{DISCUSSION}

Our study confirms that levels of physical activity are low in the UK diabetes population, with only $34 \%$ of patients taking some form of physical activity within a random two week window. Active patients were younger but were not lighter and did not have better glycaemic control. Inactivity was not associated with treatment modality in type 2 diabetes. This level of inactivity has not improved since $1990^{12}$ and is similar to that observed more recently in the US. ${ }^{13}$

Active patients with type 2 diabetes, however, can keep their weight down to the same level as active counterparts with type 1 diabetes, although inactivity seemed to be associated with a greater propensity for weight gain in type 2 diabetes (table 1). Waist circumferences will be more sensitive at detecting likely improvements in body composition from fat to muscle mass, than measurement of weight or body mass index. Unfortunately waist circumference measurements were not performed in this study.

Table 2 Different forms of physical activity and intensity

\begin{tabular}{|c|c|c|c|c|c|}
\hline \multirow[b]{2}{*}{ Activity } & \multirow{2}{*}{$\begin{array}{l}\text { Mean (SD) times } \\
\text { in the last } 2 \\
\text { weeks (n) }\end{array}$} & \multirow{2}{*}{$\begin{array}{l}\text { Mean (SD) times } \\
\text { spent (min) }\end{array}$} & \multicolumn{3}{|c|}{ No $(\%)$ with change in heart rate or breathing } \\
\hline & & & None & Small & Large \\
\hline Walking & $13.2(10.4)$ & $48.8(36.1)$ & $240(63)$ & $114(30)$ & $28(7)$ \\
\hline Gardening & $3.6(2.8)$ & 98.3 (62.8) & $98(48)$ & 100 (49) & 7 (3) \\
\hline Swimming & $2.26(1.5)$ & $56.8(19.4)$ & $18(35)$ & $27(52)$ & $7(14)$ \\
\hline General exercise & $9.25(7.1)$ & $27.9(30.3)$ & $23(27)$ & $36(43)$ & $25(30)$ \\
\hline
\end{tabular}


Table 3 Psychological variables in patients aged under 60 years

\begin{tabular}{|c|c|c|c|c|c|c|}
\hline & \multicolumn{2}{|l|}{ Active } & \multicolumn{2}{|c|}{ Non-active } & \multirow[b]{2}{*}{$\chi^{2}$} & \multirow[b]{2}{*}{ p Value } \\
\hline & Total No & No (\%) & Total No & No (\%) & & \\
\hline \multicolumn{7}{|l|}{ Agree with the statement: } \\
\hline It is difficult for me to take part in exercise & 72 & $11(15)$ & 117 & $57(44)$ & 16 & 0.0001 \\
\hline I can't exercise because there are few local facilities & 72 & $10(14)$ & 111 & $29(26)$ & 3.81 & 0.05 \\
\hline $\begin{array}{l}\text { I can't exercise because I can't afford to use the local } \\
\text { facilities }\end{array}$ & 78 & $10(13)$ & 126 & $29(23)$ & 3.2 & 0.07 \\
\hline I can't exercise because I have no spare time & 72 & $5(7)$ & 113 & $28(25)$ & 9.54 & 0.002 \\
\hline $\begin{array}{l}\text { Gentle exercise like regular walks would help my diabetes } \\
\text { control }\end{array}$ & 78 & $55(71)$ & 126 & $98(78)$ & 1.3 & 0.24 \\
\hline $\begin{array}{l}\text { Strenuous exercise like regular jogging would significantly } \\
\text { help my diabetes control }\end{array}$ & 72 & $63(88)$ & 116 & $87(79)$ & 4.30 & 0.038 \\
\hline \multicolumn{7}{|l|}{ Agree with the statement that it is quite or very unlikely that: } \\
\hline $\begin{array}{l}\text { Strenuous exercise like regular jogging causes } \\
\text { hypoglycaemia (low blood sugar) }\end{array}$ & 53 & $35(66)$ & 62 & $51(82)$ & 3.99 & 0.05 \\
\hline Gentle exercise like regular walks causes hypoglycaemia & 63 & $7(11)$ & 78 & $16(20)$ & 2.26 & 0.13 \\
\hline \multicolumn{7}{|l|}{ Agree with the statement that the risk is high or very high that: } \\
\hline My diabetes will get worse & 61 & $35(57)$ & 101 & $77(76)$ & 6.3 & 0.01 \\
\hline \multicolumn{7}{|l|}{ I am confident that I will carry out my planned exercise even if: } \\
\hline The weather is poor & 67 & $54(81)$ & 104 & $46(44)$ & 22.19 & 0.0001 \\
\hline I feel depressed & 64 & $57(89)$ & 101 & $64(63)$ & 13.22 & 0.0001 \\
\hline There is something good on television & 70 & $55(79)$ & 112 & $63(56)$ & 9.4 & 0.002 \\
\hline My friends want me to do something else & 36 & $20(56)$ & 68 & $34(50)$ & 0.3 & 0.59 \\
\hline My diabetic control has been poor recently & 60 & $48(73)$ & 107 & $81(76)$ & 0.2 & 0.66 \\
\hline $\begin{array}{l}\text { I have had more hypoglycaemic episodes than usual } \\
\text { recently }\end{array}$ & 46 & 34 (74) & 55 & $28(51)$ & 5.59 & 0.02 \\
\hline
\end{tabular}

Walking and gardening were popular activities. The levels at which these were performed, however, were usually ineffective at raising heart rate and breathing. Self perceived exertion scales have been validated as an estimation of physical activity intensity. ${ }^{20}$ In the third of patents who do exercise, only $9 \%$ did so sufficiently to achieve a "large" change in heart rate or breathing. We surmise that many active patients with diabetes exercise at suboptimal intensities, and this could explain why such patients did not have improved glycaemic control or a lower body mass index compared with inactive patients.

A recent meta-analysis concluded that exercise as a form of intervention management was highly effective at improving the levels of HbAlc in patients with diabetes. ${ }^{1}$ Several studies

Table 4 Psychological variables in patients aged over 60 years

\begin{tabular}{|c|c|c|c|c|c|c|}
\hline & \multicolumn{2}{|l|}{ Active } & \multicolumn{2}{|c|}{ Non-active } & \multirow[b]{2}{*}{$\chi^{2}$} & \multirow[b]{2}{*}{ p Value } \\
\hline & Total No & No (\%) & Total No & No (\%) & & \\
\hline \multicolumn{7}{|l|}{ Agree with the statement: } \\
\hline It is difficult for me to take part in exercise & 53 & $9(17)$ & 133 & $75(56)$ & 32.7 & 0.0001 \\
\hline I can't exercise because there are few local facilities & 50 & $14(28)$ & 120 & $43(36)$ & 0.9 & 0.32 \\
\hline $\begin{array}{l}\text { I can't exercise because I can't afford to use the local } \\
\text { facilities }\end{array}$ & 55 & $8(15)$ & 141 & $35(25)$ & 2.4 & 0.12 \\
\hline I can't exercise because I have no spare time & 55 & $16(29)$ & 141 & $42(30)$ & 0.01 & 0.92 \\
\hline $\begin{array}{l}\text { Gentle exercise like regular walks would help my diabetes } \\
\text { control }\end{array}$ & 55 & $43(78)$ & 141 & $106(75)$ & 0.20 & 0.66 \\
\hline $\begin{array}{l}\text { Strenuous exercise like regular jogging would significantly } \\
\text { help my diabetes control }\end{array}$ & 55 & $24(44)$ & 141 & $38(27)$ & 5.1 & 0.02 \\
\hline \multicolumn{7}{|l|}{ Agree with the statement that it is quite or very unlikely that: } \\
\hline $\begin{array}{l}\text { Strenuous exercise like regular jogging causes } \\
\text { hypoglycaemia (low blood sugar) }\end{array}$ & 15 & $6(40)$ & 33 & $24(72)$ & 4.7 & 0.03 \\
\hline Gentle exercise like regular walks causes hypoglycaemia & 24 & $3(13)$ & 62 & $17(27)$ & 2.1 & 0.14 \\
\hline \multicolumn{7}{|l|}{ Agree with the statement that the risk is high or very high that: } \\
\hline My diabetes will get worse & 36 & $18(50)$ & 82 & $52(63)$ & 1.87 & 0.17 \\
\hline \multicolumn{7}{|l|}{ I am confident that I will carry out my planned exercise even if: } \\
\hline I feel a bit tired & 47 & $34(72)$ & 119 & $73(61)$ & 1.78 & 0.18 \\
\hline The weather is poor & 47 & $31(66)$ & 128 & $54(42)$ & 7.8 & 0.005 \\
\hline I feel depressed & 47 & $43(92)$ & 128 & 111 (87) & 0.74 & 0.39 \\
\hline There is something good on television & 48 & $37(77)$ & 121 & $70(58)$ & 5.47 & 0.02 \\
\hline My friends want me to do something else & 34 & $18(53)$ & 79 & $43(54)$ & 0.02 & 0.88 \\
\hline My diabetic control has been poor recently & 53 & $47(89)$ & 128 & $100(78)$ & 2.7 & 0.10 \\
\hline $\begin{array}{l}\text { I have had more hypoglycaemic episodes than usual } \\
\text { recently }\end{array}$ & 14 & $7(50)$ & 31 & $26(84)$ & 5.7 & 0.02 \\
\hline
\end{tabular}


Table 5 Bivariate regression analysis of psychological variables in active and inactive patients

\begin{tabular}{|c|c|c|c|c|c|c|}
\hline Psychological variable & Odds ratio & $\mathrm{Cl}$ & p Value & $\begin{array}{l}\text { Odds ratio (adjusted } \\
\text { for age and type of } \\
\text { diabetes) }\end{array}$ & $\mathrm{Cl}$ & p Value \\
\hline It is difficult for me to take part in exercise & 0.20 & 0.12 to 0.35 & 0.0001 & 0.20 & 0.12 to 0.35 & 0.0001 \\
\hline $\begin{array}{l}\text { I can't exercise because there are few local } \\
\text { facilities }\end{array}$ & 0.57 & 0.34 to 0.96 & 0.036 & 0.57 & 0.35 to 0.96 & 0.033 \\
\hline $\begin{array}{l}\text { I can't exercise because I can't afford to use } \\
\text { the local facilities }\end{array}$ & 0.49 & 0.25 to 0.94 & 0.330 & 0.52 & 0.27 to 0.97 & 0.415 \\
\hline I can't exercise because I have no spare time & 0.24 & 0.09 to 0.016 & 0.023 & 0.32 & 0.13 to 0.78 & 0.012 \\
\hline $\begin{array}{l}\text { Gentle exercise like regular walks would } \\
\text { help my diabetes control }\end{array}$ & 0.87 & 0.54 to 1.42 & 0.585 & 0.85 & 0.53 to 1.36 & 0.490 \\
\hline $\begin{array}{l}\text { Strenuous exercise like regular jogging would } \\
\text { significantly help my diabetes control }\end{array}$ & 1.45 & 0.69 to 3.07 & 0.325 & 1.74 & 0.85 to 3.56 & 0.133 \\
\hline $\begin{array}{l}\text { Chance of strenuous exercise like regular } \\
\text { jogging causing hypoglycaemia } \\
\text { (low blood sugar) }\end{array}$ & 0.59 & 0.33 to 1.06 & 0.077 & 0.68 & 1.40 to 1.16 & 0.155 \\
\hline $\begin{array}{l}\text { Chance of gentle exercise like regular walks } \\
\text { causing hypoglycaemia }\end{array}$ & 0.0002 & 0 to $\infty$ & 0.770 & 0.19 & 0.23 to 1.54 & 0.119 \\
\hline $\begin{array}{l}\text { Risk of diabetes getting worse } \\
\text { I am confident that I will carry out my } \\
\text { planned exercise even if: }\end{array}$ & 0.65 & 0.42 to 0.99 & 0.050 & 0.70 & 0.46 to 1.07 & 0.104 \\
\hline I feel a bit tired & 2.91 & 1.88 to 4.49 & 0.0001 & 2.95 & 1.91 to 4.53 & 0.0001 \\
\hline The weather is poor & 1.38 & 0.82 to 2.33 & 0.230 & 1.30 & 0.78 to 2.18 & 0.310 \\
\hline I feel depressed & 1.62 & 1.01 to 2.60 & 0.046 & 1.40 & 0.89 to 2.21 & 0.147 \\
\hline There is something good on television & 2.24 & 1.44 to 3.49 & 0.0003 & 2025 & 1.45 to 3.47 & 0.0003 \\
\hline My friends want me to do something else & 1.02 & 0.64 to 1.63 & 0.927 & 0.97 & 0.61 to 1.54 & 0.903 \\
\hline My diabetic control has been poor recently & 1.28 & 0.80 to 2.03 & 0.300 & 1.18 & 0.75 to 1.86 & 0.465 \\
\hline $\begin{array}{l}\text { I have had more hypoglycaemic episodes } \\
\text { than usual recently }\end{array}$ & 1.29 & 0.70 to 2.39 & 0.405 & 1.22 & 0.67 to 2.21 & 0.513 \\
\hline
\end{tabular}

have shown lifestyle changes including increasing activity levels are effective in delaying the onset of diabetes in high risk patients, ${ }^{7-9}$ and more so than prescribing metformin. ${ }^{7}$ The intensity of exercise was greater than achieved by the majority of patients in our study. However in studies such as this the care package supporting patients to do this exercise was extensive. Without such resources, patients find it difficult to maintain such levels of activity. We have identified that key modifiable barriers to patients' participation in exercise include availability of cheap facilities and education regarding the health benefits of exercise and mechanisms of avoiding hypoglycaemia.

We demonstrated that inactivity was more commonly seen in older patients as has been shown previously. ${ }^{13}{ }^{21}$ We thus studied causes for inactivity in those under 60 years separately from those over 60 years. Inactivity in older patients (table 4) was associated with lack of self efficacy, feelings of tiredness, and distraction by good television programmes. All these factors were also important for younger patients, but lack of time, fear of diabetes getting worse, poor weather, and feeling depressed were also important associations with inactivity in the younger group (table 3).

Lack of confidence in ability to perform exercise was the main barrier to performing exercise in our study, and this has been a consistent finding in previous US studies. ${ }^{13} 1621$ Over the last 10 years little progress has been made in enabling patients to overcome these difficulties, however. Setting modest but realistic goals, and helping patients to undertake exercise are likely to be effective at changing behaviour patterns, ${ }^{22}$ and recent attempts to help patients with diabetes using exercise consultation seem to be encouraging. ${ }^{23}$

Patients need encouragement to take some form of physical activity despite feelings of tiredness, as ironically such feelings can be improved by undertaking exercise. ${ }^{10}$ Although it has previously been suspected from indirect associations, we have clearly demonstrated an association between television viewing and inactivity. It is unfortunate that television viewing has such an unfortunate effect on the health of the nation, and it is a difficult barrier to overcome.
Poor weather reduced activity levels in this UK population, which should encourage the development of affordable indoor exercise facilities. Other groups have identified that good friend support, ${ }^{16}$ education, ${ }^{21}$ and income ${ }^{13}$ are all additional features which are associated with increased activity levels.

These reasons probably underpin the proven long term advantages of tailoring exercise regimens to the individual and making them diabetes specific. ${ }^{24}$ Previous studies suggest that long term compliance is best with individualised lifestyle advice and moderate intensity exercise, which is home based. ${ }^{232526}$ The real financial costs of support mechanisms to enable patients to participate in useful levels of activity may be more than are generally recognised.

The number of patients with diabetes who participate in significant physical activity is disappointing (34\%), and in many of these the intensity of exercise is minimal. Local councils need to consider the availability and cost of exercise facilities in the community. More organised groups may help mutual encouragement. Diabetes teams may need to spend more time counselling about the social aspects of promoting physical activity in addition to educating about the health benefits of physical activity. The use of psychologists, physiotherapists, or exercise physiologists within the diabetes team needs exploring.

\section{ACKNOWLEDGEMENTS}

We thank Jan Kennedy who helped with this survey, and Simon Ogston and Robert Flynn for their help with the statistics

\section{Authors' affiliations}

N Thomas, Ninewells Hospital and Medical School, Dundee, UK

E Alder, Director of Research Faculty of Health and Life Sciences, Napier University, Edinburgh, UK

G P Leese, Ninewells Hospital And Medical School, Dundee, UK

\section{REFERENCES}

1 Boulé NG, Haddad E, Kenny GP, et al. Effects of exercise on glycaemic control and body mass in type 2 diabetes mellitus. A meta-analysis of controlled clinical trials. JAMA 2001;286:1218-27. 
2 Gu K, Cowie CC, Harris MI. Diabetes and decline in heart disease mortality in US adults. JAMA 1999;281:1291-7.

3 Berlin JA, Colditz GA. A meta-analysis of physical activity in the prevention of coronary heart disease. Am J Epidemiol 1990;132:612-28.

4 Blair SN, Kohl HW, Paffenbarger RS Jr, et al. Physical fitness and all-cause mortality. JAMA 1989;262:2395-401.

5 Haennel RG, Lemire F. Physical activity to prevent cardiovascular disease. How much is enough? Can Fam Physician 2002;48:65-71.

6 Ivy JL, Zderic TW, Fogt DL. Prevention and treatment of non insulin diabetes mellitus. Exerc Sport Sci Rev 1999;27:1-35.

7 Knowler WC, Barrett Connor E, Fowler SE, et al. Reduction in the incidence of type 2 diabetes with lifestyle intervention or metformin. N Engl J Med 2002;346:393-403.

8 Tuomilehto J, Lindstrom J, Eriksson JG, et al. Prevention of type 2 diabetes mellitus by changes in lifestyle among subjects with impaired glucose tolerance. N Engl J Med 2001;344:1343-50.

9 Pan XR, Li GW, Hu YH, et al. Effects of diet and exercise in preventing NIDDM in people with impaired glucose tolerance, The Da Qing IGT and Diabetes Study. Diabetes Care 1997;20:537-44.

10 Fox KR. The influence of physical activity on mental wellbeing. Public Health Nutrition 1999;2(3A):411-8.

11 Egede LE. Zheng D. Modifiable cardiovascular risk factors in adults with diabetes: prevalence and missed opportunities for physician counselling. Arch Intern Med 2002; 162:427-33.

12 Ford ES, Herman WH. Leisure-time physical activity patterns in the US diabetic population. Findings from the 1990 National Health Interview Survey-Health Promotion and Disease Prevention Supplement. Diabetes Care 1995; 18:27-33.

13 Nelson KM, Reiber G, Boyko EJ. Diet and exercise among adults with type-2 diabetes (findings from NHANES III). Diabetes Care 2002;25:1722-8.

14 Clark DO. Perceived barriers and facilitators to exercise among older low income adults. Journal of Clinical Geropsychology 1998;5:51-62.
15 Dishman RK. Sallis JF, Orenstein DR. the determinants of physical activity and exercise. Public Health Rep 1985;100:158-71.

16 Sallis JF, Hovell MF, Hofstetter CR, et al. A multivariate study of determinants of vigorous exercise in a community sample. Prev Med 1989;18:20-34.

17 Adams PF, Benson V. Current estimates from the National Health Interview Survey, 1990. Series 10: Data from the national health survey. No 181. Vital Health Statistics 1991:1-121.

18 Schwarzer R. Fuchs R. Self-efficacy and health behaviours. In: Conner M, Norman P, eds. Predicting health behaviour: research and practice with social cognition models. Buckingham, UK: Open University Press, 1996:163-96.

19 Morris AD, Boyle DIR, MacAlpine R, et al. The Diabetes Audit and Research study in Tayside Scotland (darts) study: electronic record linkage to create a diabetes register. BMJ 1997;315:524-8.

20 Hillsdon M, Thorogood M, Anstiss T, et al. Randomised controlled trials of physical activity promotion in free living populations: a review. J Epidemiol Community Health 1995;49:448-53.

21 Hays LM, Clark DO. Correlates of physical activity in a sample of older adults with type-2 diabetes. Diabetes Care 1999;22:706-12.

22 Aljasem LI, Peyrot $M$, Wissow $L$, et al. The impact of barriers and self-efficacy on self-care behaviors in type-2 diabetes. Diabetes Education $2001 ; 27: 393-404$.

23 Kirk AF, Higgins LA, Hughes AR, et al. A randomised controlled trial to study the effect of exercise consultation on the promotion of physical activity in people with type-2 diabetes: a pilot study. Diabet Med 2001;18:877-82.

24 Albright AL, Franz M, Hornosby G, et al. American College of Sports Medicine position stand. Exercise and type 2 diabetes. Med Sci Sports Exerc 2000;32:1345-60.

25 Weyer C, Linkeschowa R, Heise T, et al. Implications of the traditional and the new ACSM physical activity recommendations on weight reduction in diet treated obese subjects. Int J Obes Relat Metab Disord 1998;22:1071-8.

26 Loughlan C, Mutrie N. An evaluation of the effectiveness of three interventions in promoting physical activity in a sedentary population. Health Education Journal 1997; 56:154-65. 